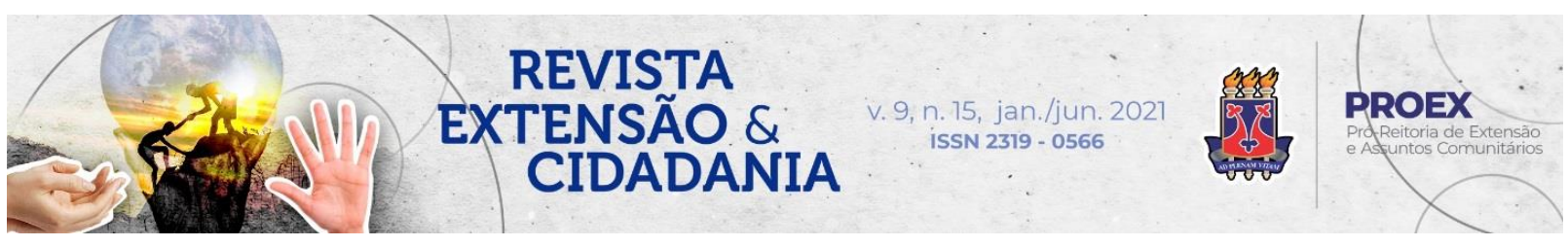

DOI: $10.22481 /$ recuesb.v9i15.8726

\title{
SERVIÇO DE ATENDIMENTO EM SAÚDE MENTAL A POLICIAIS MILITARES: UMA AÇÃO EXTENSIONISTA
}

\author{
Mental health service to police: an extensionist project
}

Odilza Lines de Almeida ${ }^{1}$

Ana Lúcia Castilhano de Araújo ${ }^{2}$

Ana Mara Dutra Souza ${ }^{3}$

\begin{abstract}
Resumo: Trata-se de relato de experiência de projeto para atendimento a policiais militares com vistas à prevenção e tratamento de transtornos mentais tendo em vista os índices de adoecimento mental dessa população em virtude da atividade exercida e potencializada pelo crescente número de mortes violentas dos pares e pelos agentes estressores específicos da profissão. O objetivo da proposta é fomentar a cultura de prevenção do sofrimento mental e contribuir para um melhor preparo desses agentes em suas atividades no sistema de defesa social. Os atendimentos são realizados por um grupo de professores da Universidade Estadual do Sudoeste da Bahia, que utilizam diferentes abordagens psicoterápicas, no Núcleo de Práticas Psicológicas ligado ao Curso de Psicologia da instituição sob a forma de Projeto de Extensão. Em três anos de existência, o projeto realizou 353 atendimentos até fevereiro de 2020. Concluise que o projeto se mostrou importante para a população-alvo que tem buscado e se implicado com essa modalidade de atendimento psicológico. O projeto é realizado em parceria com a polícia militar, a qual vem se empenhando em atividades de sensibilização e divulgação do projeto, entendendo os aspectos de confidencialidade e da necessidade de o sujeito se implicar na atividade proposta. As demandas se referem a conflitos entre a identidade pessoal e profissional, fatores estressores relacionados ao trabalho, assim como questões associadas à dependência química e aos diagnósticos psiquiátricos como transtorno de humor.
\end{abstract}

Palavras-chave: Projeto de extensão. Policial militar. Atendimento psicológico.

Abstract: This is a report of a project to assist military police officers for prevention and treatment of mental disorders because of the mental illness rates of this population due to the activity exercised and enhanced by the increasing number of violent deaths of peers and by profession-specific stressors. The proposal aims to foster a culture of prevention of mental

\footnotetext{
${ }^{1}$ Psicóloga; Doutora em Saúde Coletiva. Professora da Universidade Estadual do Sudoeste da Bahia, Vitória da Conquista, Bahia, Brasil. Orcid 0000-0002-3893-3952 E-mail odilzalines@uesb.edu.br

2 Psicóloga; Doutora em Educação. Professora da Universidade Estadual do Sudoeste da Bahia, Vitória da Conquista, Bahia, Brasil. Orcid 0000-0003-3554-828X E-mail: alcastilhano@uesb.edu.br

${ }^{3}$ Psicóloga, Doutora em Planificación Territorial. Professora da Universidade Estadual do Sudoeste da Bahia, Vitória da Conquista, Bahia, Brasil. Orcid 0000-0002-1029-8686 E-mail: anoca222@ hotmail.com
} 
suffering and to contribute to better preparation of these agents in their activities in the social defense system. The consultations are performed by a group of professors from the State University of Southwest Bahia, who use different psychotherapeutic approaches, at the Psychological Practices Center linked to the Psychology Course of the institution in the form of an Extension Project. In three years of existence, the project carried out 353 calls until February 2020. It is concluded that the project proved to be important for the target population that has sought and been involved with this type of psychological assistance. The project is carried out in partnership with the military police, which has been engaged in activities to raise awareness and disseminate the project, understanding the aspects of confidentiality and the need for the subject to be involved in the proposed activity. The demands refer to conflicts between personal and professional identity, stressors related to work, as well as issues related to chemical dependence and psychiatric diagnoses such as mood disorder.

Keywords: Extension project. Police. Psychological support.

\section{Introdução}

Já há algum tempo se sabe que a profissão de policial é uma das atividades laborais que abriga inúmeros fatores potencialmente estressores, características reconhecidas pela própria Organização Mundial da Saúde (OMS), quando afirmou que "A atividade policial é considerada a segunda profissão maior causadora de estresse do mundo, sendo superada apenas para a mineração, ou seja, este ofício é um dos mais arriscados para a saúde e bem estar físico e mental". (OMS, 1998, p. 6).

Contudo, somente na década de 1990, com o agravamento dos problemas criminais e dos riscos de violência no campo da segurança pública brasileira, é que o contexto de vitimização tanto de civis quanto de policiais começou a ser alvo de estudos mais sistematizados. Para além das mortes violentas de policiais em níveis que, a depender do local, crescem demasiadamente a cada ano, justifica-se a intervenção no contexto de adoecimento mental, devido à vulnerabilização e ao risco de sofrimento provocado ou potencializado por agentes estressores laborais da profissão de policial militar que incide tanto sobre o profissional, como sobre seus familiares. Isso sem falar da incidência desse sofrimento sobre a prática profissional e a segurança pública.

Neste sentido, existe uma gama de fatores que podem influenciar a saúde do trabalhador policial, podendo desencadear quadros de transtornos de ansiedade generalizada, quadros fóbicos, pânico, doenças psicossomáticas, entre outros. Os estressores podem variar desde questões relativas aos valores institucionais da cultura militar com hierarquia rígida e com pouca autonomia, promotora de um ethos machista atrelado ao culto da masculinidade, em que a sensibilidade humana precisa ser renunciada na lógica de formação de um habitus guerreiro

Revista Extensão \& Cidadania, v. 9, n. 15, p. 209-217, jan./jun. 2021. 
voltado ao combate, até a própria percepção do agente policial sobre o contexto de risco ao qual se expõe e das condições objetivas de trabalho e valorização institucional dispensada à classe de trabalhadores da segurança pública. Isso tudo se soma a um baixo nível de aprovação e apoio popular, muitas vezes referendado pela mídia.

Em pesquisa realizada em 2014 e publicada em 2017, 1.850 policiais do Estado da Bahia foram consultados acerca da ideação suicida e de fatores envolvendo o sentimento de (in)satisfação em relação a alguns temas no ambiente de trabalho. Em relação à ideação suicida, $14 \%$ dos entrevistados "pensou, mas não tentou" e 3\% tentaram. Desses $3 \%$ que tentaram o suicídio, 49 policiais $(81,7 \%)$ foram do sexo masculino e $11(18,3 \%)$, do sexo feminino (MIRANDA; MENEZES; NUNES, 2017, p. 63).

Já em relação à (in)satisfação no ambiente de trabalho, a mesma pesquisa informou que $40 \%$ dos policiais investigados estão insatisfeitos ou muito insatisfeitos em trabalhar na Polícia Militar da Bahia (PMBA); 68,5\% estão insatisfeitos ou muito insatisfeitos em relação ao regulamento disciplinar da instituição; 89\% estão insatisfeitos ou muito insatisfeitos em relação às oportunidades de ascensão na carreira e $84,1 \%$ estão insatisfeitos ou muito insatisfeitos com a valorização da polícia por parte da sociedade.

Muitos dos achados nessa pesquisa com a PMBA, segundo os autores, foram também encontrados na Polícia Militar do Estado do Rio de Janeiro (PMERJ) (MIRANDA, 2016), e dizem respeito a fatores associados ao comportamento suicida, a saber: a insatisfação com o trabalho na Polícia; desvalorização profissional (dentro e fora da Polícia), perdas de um colega e/ou amigo policial no exercício das atividades de trabalho e percepções de vitimizações por agressões não letais envolvendo agentes da polícia. Insulto, humilhação ou xingamento e amedrontamento ou perseguição foram as vitimizações mais abordadas pelos entrevistados que declararam ideação suicida e tentativa de suicídio em ambas as organizações policiais militares (MIRANDA; MENEZES; NUNES, 2017, p. 63)

Miranda, Menezes e Nunes (2017), portanto, concluem o estudo informando que as narrativas analisadas corroboram com os fatores de risco ocupacional e interpessoal/individual dos casos de ideação e tentativas de suicídio comunicadas pelos participantes da pesquisa aplicada entre policiais militares da PMBA integrados à Rede EaD SENASP - Secretaria Nacional de Segurança Pública. Grande parte das narrativas evidencia que a Polícia Militar do estado da Bahia carece de políticas de intervenção do adoecimento psíquico e prevenção ao comportamento suicida. É nessa direção que recomendamos formulações de ações institucionais de prevenção ao adoecimento mental, como por exemplo, palestras de

Revista Extensão \& Cidadania, v. 9, n. 15, p. 209-217, jan./jun. 2021 
sensibilização, a produção e divulgação de cards informativos ou folders para a prevenção e o oferecimento de cursos de formação de agentes multiplicadores de prevenção do suicídio. (MIRANDA; MENEZES; NUNES, 2017, p. 64)

Em uma outra pesquisa sobre possibilidades de tratamento de policiais adictos, que resultou em uma dissertação de um Mestrado Profissional em Gestão e Políticas de Segurança Pública, da Universidade Federal da Bahia em parceria com a Secretaria Nacional de Segurança Pública (SENASP), dados revelam que, do total de 1.719 registros de atendimento pelo Serviço de Valorização Profissional (SEVAP/PMBA) e encaminhamento para tratamento de transtornos mentais e comportamentais nos anos de 2009 a 2011, os fenômenos que mais apareceram foram, em primeiro lugar: transtornos de humor (afetivo) com 626 casos; em segundo lugar: transtornos neuróticos, transtornos relacionados com o estresse e transtornos somatoformes com 504 casos; em terceiro lugar: esquizofrenia, transtorno esquizotípicos e transtornos delirantes, com 418 casos; em quarto lugar: transtornos mentais e comportamentais devido ao uso de substâncias psicoativas, com 109 casos; em quinto lugar: transtornos mentais orgânicos, inclusive os sintomáticos, com 45 casos. (SANTOS, 2013). Outros fenômenos foram categorizados, mas não consistiram em grande relevância quantitativa verificada com os anteriores.

Diante de tantos indicadores de sofrimento mental, esta ação extensionista busca, através de parceria com o Comando Regional da Polícia Militar, intervir junto a esses agentes do sistema de defesa social com vistas ao aprimoramento do manejo das situações de risco e vulnerabilidade bem como de garantir uma melhor prestação dos seus serviços à comunidade. De acordo com De Medeiros (2017, p. 14), “a extensão pode ser entendida como o meio através do qual a comunidade pode questionar a ciência e apresentar a ela suas demandas". Dessa forma, podemos considerar esta ação como uma resposta possível da Universidade ao questionamento e demanda social sobre este fenômeno.

\section{Metodologia}

O projeto de Atendimento a Policiais Militares foi iniciado em 2018, fruto de parceria entre a Universidade Estadual do Sudoeste da Bahia e a Polícia Militar da Bahia. A iniciativa por parte da polícia se deu como política de prevenção e cuidado à saúde mental dos trabalhadores e trabalhadoras especialmente considerando os crescentes índices de suicídio entre policiais baianos, o que motivou a procura por atendimento psicológico no Núcleo de

Revista Extensão \& Cidadania, v. 9, n. 15, p. 209-217, jan./jun. 2021. 
Práticas Psicológicas (NUPPSI), da Universidade com o intuito de atender a microrregião do Comando Sudoeste. O projeto se articula com o NEPP - Grupo de Pesquisa e Estudos em Prisões, Violência e Direitos Humanos, bem como com conteúdo de disciplinas da área clínica, institucional e social ofertadas no Curso de Psicologia, das quais as professoras envolvidas são docentes.

Até abril de 2021, foram realizados 383 atendimentos, cujas queixas principais são inadaptação e relações no trabalho; relacionamentos familiares; condições psiquiátricas como diagnóstico de TAG ou transtorno bipolar; dependência química; ideação suicida, entre outros. Até o momento, o projeto conta com uma demanda mista, composta de homens e mulheres com idades que variam de 30 a 50 anos.

A instituição parceira se responsabilizou, até o momento, pela sensibilização dos seus quadros e divulgação do serviço que é realizado no NUPPSI. Os atendimentos são realizados a partir de demanda espontânea, embora haja, por parte do Serviço de Valorização Profissional da instituição, encaminhamentos em situações de risco, mas que não são de anuência obrigatória e essa é a condição para atendimento desses profissionais. Um dos princípios importantes para o desenvolvimento do projeto foi o modelo de trabalho apenas com os docentes do curso na função de psicoterapeutas por conta do compromisso profissional regulamentado pelo conselho profissional.

Os interessados no atendimento ligam diretamente para o NUPPSI e agendam com o Serviço. Os atendimentos são semanais e cada profissional utiliza sua abordagem de formação nos atendimentos. Até o momento, as abordagens utilizadas são psicanálise, terapia cognitivacomportamental e psicologia analítica. Não há limites no que se refere ao número de sessões que depende do quadro apresentado, da abordagem utilizada e da adesão da pessoa atendida.

Da mesma forma, alguns critérios e flexibilização nos atendimentos são decididos pela psicoterapeuta responsável pelo atendimento com aquela pessoa. Alguns policiais viajam de outros municípios para serem atendidos no NUPPSI. Alguns trabalham sob regime de plantão respeitando escalas, e isso muitas vezes não permite o cumprimento de sessões em dias fixos da semana. Este pode ser um ponto relevante na adesão ao trabalho psicoterapêutico. Além do atendimento psicoterápico, os policiais e seus familiares têm acesso ao atendimento psiquiátrico, que é uma parceria do NUPPSI com a Prefeitura Municipal de Vitória da Conquista e a Residência de Psiquiatria do SUS-BA.

Durante o período de funcionamento deste projeto, sempre que necessário, os policiais foram encaminhados para tal atendimento, uma vez que vários estudos apontam que, em alguns

Revista Extensão \& Cidadania, v. 9, n. 15, p. 209-217, jan./jun. 2021. 
casos, há uma maior eficácia do tratamento conjugado psicoterapia/farmacoterapia. A demanda de atendimento de familiares dos policiais é direcionada para os atendimentos convencionais do NUPPSI, como o plantão psicológico. Cabe ressaltar que, após o advento da crise sanitária em março de 2020, o atendimento passou a ser online, o que tem possibilitado alcançar mais policiais em outras cidades que compõem a microrregião atendida pelo Projeto.

Periodicamente são realizadas reuniões entre os responsáveis pelo projeto das duas instituições com o objetivo de avaliação e alinhamento das propostas da política adotada pela corporação e os critérios e planejamento no aspecto clínico. Essas reuniões têm sido fundamentais para a compreensão de pontos importantes referentes à cultura policial e para pensarmos em desdobramentos do projeto a partir da identificação de situações estressoras institucionais.

É importante destacar que os policiais atendidos no NUPPSI assinam um documento de Consentimento Livre e Esclarecido no qual se declaram cientes do contrato de atendimento, são informados sobre questões como o sigilo profissional e também oferecem sua anuência para o uso dos dados gerais para fins de pesquisa e construção do conhecimento acadêmico. Como se trata de um serviço escola de psicologia, esse é um fato importante dada a característica do NUPPSI de se tratar de um espaço de ensino que integra também a extensão e a pesquisa. Sobre a produção científica em extensão universitária, Nogueira (2001, p. 11) aponta "o compromisso social da Universidade na busca da solução dos problemas mais urgentes da maioria da população". Essa busca se assenta no diálogo entre os conhecimentos e na instrumentalização das práticas, em um processo dinâmico de difusão dos resultados consolidados no ensino e na pesquisa. (NOGUEIRA, 2005).

\section{Resultados e discussão}

O projeto é pioneiro na finalidade de reunir duas instituições públicas em parceria para atuar no campo da saúde mental dos profissionais militares e da segurança pública. Apesar de ser relativamente recente, apresenta resultados positivos tanto nos atendimentos quanto no apoio à instituição parceira em seu trabalho de valorização profissional. Da mesma forma, a conscientização por parte dos policiais sobre a importância do cuidado com a saúde em geral, e a saúde mental, em especial, é um fator que certamente tem um impacto significativo nas vidas de todos os envolvidos. Neste sentido, ressaltamos o objetivo de fomentar a cultura de

Revista Extensão \& Cidadania, v. 9, n. 15, p. 209-217, jan./jun. 2021. 
prevenção ao sofrimento mental colaborando na melhoria do preparo dos profissionais do sistema de defesa social.

O fato de a oferta de atendimento ter se iniciado por iniciativa da corporação e a opção pelo trabalho ser realizado sob demanda espontânea tem se mostrado acertada. Essa opção reafirma o compromisso do projeto e dos atendimentos com o sigilo e com os objetivos, voltados para a pessoa. Outro ponto que consideramos acertado foi a opção de designar apenas profissionais para os atendimentos. Isso possivelmente aponta para a facilidade do vínculo com abertura para a confiança considerando o sigilo profissional.

Experiências anteriores na cidade com o atendimento a policiais a partir do trabalho de estagiários de psicologia em outras instituições apresentou algumas situações imprevistas, em grande parte, relacionadas com a condição de discentes, e não de profissionais devidamente regulamentados por um conselho profissional, o que possivelmente implica em uma postura e um enquadre que tende a ser mais aceito e a gerar melhores resultados.

Há outras iniciativas de apoio, aconselhamento e terapias oferecidas em outras modalidades, algumas delas dentro da própria corporação por militares com formação em psicologia e parcerias com instituições como igrejas e cursos de psicologia em outras universidades e faculdades. A ampliação de opções é algo interessante, pois possibilita ao policial optar por uma abordagem ou modalidade que corresponda às suas questões subjetivas. No caso específico do projeto aqui apresentado, ressalta-se a proposta de atendimento psicoterápico por psicólogas civis com um compromisso laico.

Partindo da demanda equitativa entre os gêneros e faixa etária, pode-se refletir tanto em relação ao trabalho de sensibilização por parte do SEVAP, como também em relação à mudança de mentalidade dos profissionais que procuram o serviço. A polícia, especialmente a militar, apresenta características históricas de identificação patriarcal, ou a partir de uma figura masculina predominante, que certamente traz diversas questões aos profissionais, sendo que muitas delas são abertamente abordadas na psicoterapia. Pretendemos apresentar questões como essa em outro texto, com detalhes clínicos e de demanda associados com as questões sociais e culturais das pessoas atendidas no serviço. No entanto, deixamos a questão apontada aqui como forma de sinalizar aspectos importantes do trabalho desenvolvido no projeto.

A escolha da profissão de policial militar é assunto recorrente na psicoterapia, trazido tanto por homens como por mulheres. Em alguns casos, o fato de contar com uma estrutura e uma rotina organizada e disciplinada pode apontar para fatores considerados positivos para a vida de jovens que escolhem a carreira militar. É possível que essa escolha aponte para uma

Revista Extensão \& Cidadania, v. 9, n. 15, p. 209-217, jan./jun. 2021. 
necessidade de disciplina e estabilidade na vida, algo que não costuma ser muito simples na juventude. $\mathrm{O}$ fato de realizarem concurso público e poderem contar com uma carreira também se mostra como significativo. Também, e talvez não menos importante, especialmente para os homens, a questão da autoridade social, e do imaginário ligado à força também parecem significativos na escolha.

A questão do sigilo tem se mostrado significativa para os bons resultados do trabalho, sendo importante, não só em relação ao código de ética profissional do psicólogo, como também uma preocupação dos policiais atendidos. A garantia expressa do sigilo, assim como o princípio da demanda espontânea podem ser considerados pontos importantes para a constituição do vínculo e para o desenvolvimento do trabalho psicoterapêutico. Para profissionais ligados a uma instituição militar com as características históricas e sociais que a PMBA apresenta, tornase significativa a garantia de um trabalho realizado em/por instituição não militar, de caráter civil, cujo processo psicoterapêutico se processe, desde o início, sob a perspectiva humana e não militarizada.

Um ponto importante a destacar está relacionado aos conflitos entre pares. Identificado como um dos fatores estressores de maior impacto na saúde mental de trabalhadores, os conflitos com colegas de trabalho no meio militar apresentam situações bem mais complexas em função da hierarquia à qual esses trabalhadores estão submetidos. O nível de tensão é grande e podemos observar com frequência seu efeito na adaptação desses indivíduos ao trabalho e à vida social, assim como na formação de crises de ansiedade e outras respostas que podem levalos a quadros complexos com severos efeitos sobre sua saúde mental.

\section{Conclusão}

A partir desses três anos de experiência com essa população, identificamos vários dados que confirmam os relatos de pesquisa em segurança pública e saúde mental do trabalhador policial militar. Neste sentido, acreditamos que o desenvolvimento de uma pesquisa para discutir esses dados em contexto científico seja, não só uma opção viável como necessária, tanto para reafirmar a indissociação entre ensino, pesquisa e extensão como para de fato, dialogarmos com o campo científico da área. Um dado que poderia ser destacado como relevante na escuta realizada é a questão da escolha da profissão, da identificação com o culto à masculinidade e ao papel de poder e força diante de si e dos seus pares e da adaptação à instituição militar. Nesta escolha observa-se também a busca por estabilidade financeira

Revista Extensão \& Cidadania, v. 9, n. 15, p. 209-217, jan./jun. 2021. 
anunciando uma dupla motivação que impacta na imagem de si e na dificuldade de mudanças na carreira quando apresenta dificuldade para se adaptar ao ethos militar.

Neste contexto, os assistidos apontam para necessidade de mudanças na cultura organizacional, tais como um melhor aproveitamento das suas habilidades e competências nas funções exercidas bem como uma porta de entrada única na admissão dos policiais, o que culminaria em possibilidades de ascensão e desenvolvimento na carreira.

Este trabalho tem mostrado que, cada vez mais, torna-se imprescindível a parceria interinstitucional para alcançarmos a comunidade e, em especial, pessoas e instituições diretamente ligadas às funções essenciais no cotidiano do entorno no qual a nossa Universidade está inserida, permitindo, desse modo, a transferência de conhecimento e tecnologias.

\section{Referências}

DE MEDEIROS, Márcia Maria. A extensão universitária no brasil - um percurso histórico. Revista Barbaquá, Dourados, v. 1, n. 1, p. 9-16, jan./jun. 2017

MIRANDA, Dayse (org.). Por que os policiais se matam? Diagnóstico e prevenção do comportamento suicida na polícia militar do estado do Rio de Janeiro. Rio de Janeiro: Mórula Editorial, 2016.

MIRANDA, Dayse; MENEZES, Lidiane; NUNES, Pablo. As percepções do comportamento suicida na Polícia Militar do Estado da Bahia. Revista Brasileira de Psicologia, Salvador, v. 4, n. 1, p. 62-65, 2017.

NOGUEIRA, Maria das Dores Pimentel. Extensão universitária no Brasil: uma revisão conceitual. In: FARIA, Dóris Santos de (org.). Construção conceitual da extensão universitária na América Latina. Brasília-DF: Universidade de Brasília, 2001.

NOGUEIRA, Maria das Dores Pimentel. Políticas de extensão universitária. Belo Horizonte: Ed. da UFMG, 2005.

OMS - Organização Mundial de Saúde. Saúde Pública. São Paulo, 1998.

SANTOS, Ana Cláudia Maria dos. A interseção entre saúde e segurança pública: um estudo sobre prevenção, reabilitação e reinserção de policiais militares adictos. 124 f. 2013. Dissertação (Mestrado em Direito) — Faculdade de Direito, Universidade Federal da Bahia, Salvador, 2013.

Recebido: 10.05.2021

Aceito: 19.06 .2021

Revista Extensão \& Cidadania, v. 9, n. 15, p. 209-217, jan./jun. 2021. 